\title{
Alfred North Whitehead's Process and Reality
}

\author{
Peter Simons \\ Trinity College Dublin
}

Charles W. Dement (1953-2005) in memoriam

That low man seeks a little thing to do,

Sees it and does it:

This high man, with a great thing to pursue,

Dies ere he knows it.

Robert Browning

\begin{abstract}
This review of Whitehead's philosophical magnum opus gives a brief description of the system, and highlights its merits and defects. The book is about how things come to be and pass away. Its often arcane vocabulary discloses a thoroughly worked out metaphysical scheme in which atomic events are the basic individuals, and relations of "prehension" link them and the forms or eternal objects they exemplify. Among the questionable features are Whitehead's panpsychism, teleology, Platonism and theism. Among its positive features are its deployment of a method of extensive abstraction to recover geometry from atomless space-time, and its plausible account of enduring substances. Supremely brilliant is Whitehead's speculative method, which links a system of categories with principles governing them and an ultimate reality which is as it is only accidently. Expressive and conceptual difficulties notwithstanding, it is perhaps the most significant metaphysical treatise of our time.
\end{abstract}

\section{Keywords}

Whitehead, process, cosmology, metaphysics, categories 


\section{Introduction}

This book has good claims to be the greatest metaphysical treatise for many years, certainly since the beginning of the twentieth century. Process and Reality: A Study in Cosmology (hereafter: $P R$ ) is based on the Gifford Lectures that Whitehead gave in Edinburgh a few years ago. It is Whitehead's foremost philosophical work and for importance its only peer among his works is the very different Principia Mathematica, co-authored of course with his former student Mr. Bertrand Russell. Remarkably, Professor Whitehead has been a professional philosopher for only a little over five years, yet this book clearly marks the culmination of his transformation from mathematician to metaphysician. That journey has taken more than twenty years: it began with his Royal Society memoir 'On Mathematical Concepts of the Material World' and progressed through the natural philosophy of $A n$ Enquiry Concerning the Principles of Natural Knowledge, The Concept of Nature, and Science and the Modern World, to this work. It is rapidly emerging as the undisputed chef d'oeuvre of what is becoming known as process philosophy, and Whitehead the principal prophet of that genre. Its admirers in North America and continental Europe defend it with a devotion that in some cases borders on the fanatical, while its detractors, principally from the new analytical tradition, and led as in so many things by Mr. Russell, consider Whitehead's most recent work obscure, confused, woolly and mystical, not worth the effort of reading or trying to understand. We shall take issue with both extremes.

We must first say something about the text. $P R$ is long, rich, and difficult, and it gives up its secrets only through dogged persistence. It comes in five parts: I, The Speculative Scheme; II, Discussions and Applications; III, The Theory of Prehensions; IV, The Theory of Extension; V, Final Interpretation. Of these I and V are excessively compressed, while II and III are overly expansive. IV seems about right. The book is in general markedly more rhapsodic in style than the foregoing works of natural philosophy. Traversing similar ground from several perspectives in the different parts, it is repetitive, and could have benefitted from a sterner redaction than Whitehead seems to have been prepared to afford it. On the other hand, some crucial passages are terse to the point of near impenetrability. A comparison between the concurrent British and American editions reveals a slew of major and minor discrepancies, and it is clear that Whitehead's evident disinterest in the mechanics of proofreading will leave a nasty legacy of misprints and inconsistencies. These will only be remedied by the heroic but as yet unpublished Corrected Edition of David Ray Griffin and 
Donald W. Sherburne. No other edition should be used, and our page references will be to this.

Between the judgmental extremes about Whitehead in general and $P R$ in particular, it is hard to find neutral ground from which to appraise his work critically, and impossible to please everyone when doing so. This review aspires to follow the critical but sympathetic Manchester tradition of Dorothy Emmet and Wolfe Mays, both of whom struggle to translate Whitehead's ideas into a more transparent idiom in order to assess them for their truth-values.

\section{Speculative Philosophy}

The term 'cosmology' in the subtitle is instructive: it shows Whitehead is out to give an overall philosophical account of what goes on throughout space and time. His acknowledged models in the enterprise are two prior cosmologists: Plato of Timaeus and Newton of the Scholium of Principia. One would expect a philosopher of physics to prefer Newton, but Whitehead has been critical of Newton's abstractions and simplifications for many years, most especially the idea of "simple location", whereby matter is passively at a place. This for Whitehead cannot explain how things come to be. While accepting that Newton's scientific hypotheses are more accurate than Plato's, he considers that "what [Plato's cosmology] lacks in superficial detail, it makes up for by its philosophic depth" (93). As a result, he leans much more towards Plato, to whose work he notably describes the European philosophical tradition as "a series of footnotes" (39). While Whitehead cites other modern philosophers from Galilei to Kant, emphasizing Locke in particular, he uses in each case just a few of their ideas as points of departure for his own thinking, which he asks to be judged for itself.

Whitehead also calls his work "an essay in Speculative Philosophy" (3), which he defines as "the endeavour to frame a coherent, logical, necessary system of general ideas in terms of which every element of our experience can be interpreted" (ibid.). Given the ubiquity (to be discussed below) of experience, this means he is aspiring to provide, at least in schematic outline, that to which every metaphysician should indeed aspire: a theory of everything. The ferocity of this ambition is matched only by Whitehead's disarming modesty: "There remains the final reflection, how shallow, puny, and imperfect are efforts to sound the depth in the nature of things" (xiv). He follows this immediately with a warning: "In philosophical discussion, the merest hint of dogmatic certainty as to finality of statement is an exhibition of folly" (ibid.). I wonder whether at this point he was mentally comparing his 
fallibilism with the markedly less modest convictions expressed in the Preface to Wittgenstein's recent Tractatus Logico-Philosophicus.

The first Part, 'The Speculative Scheme', consisting of three chapters, 'Speculative Philosophy', 'The Categoreal Scheme' ${ }^{1}$ and 'Some Derivative Notions' is a tour de force of compressed statement, setting out Whitehead's position. It is more or less incomprehensible on a first reading, and indeed it is likely that very few readers will understand every sentence in it. A good test for how one is progressing with understanding the book is how much of this part becomes clearer on returning to it subsequently after further reading.

Whitehead's requirements for metaphysics (the more common name for his speculative philosophy) seem to me to be completely right. It is about absolutely everything, or it falls short of its aim. It is a general scheme rather than a mere conjunctive encyclopaedia, otherwise it is not metaphysics. It is informed by contemporary science, otherwise it will be obsolete or inapplicable. It should be logically consistent, and yet also be able to explain how logic fits into the world. And finally it has to be coherent, in that the fundamental notions are all interwoven so that none can be taken in complete abstraction from the others. This last requirement, the most difficult to satisfy and the most infrequently recognised, let alone satisfied, is what lifts Whitehead's understanding of metaphysics above the ordinary. We shall see how he tries to fulfil it, and how he falls short.

\section{Becoming and Perishing}

Having set out the context and framework, it is time to say what $P R$ is fundamentally about. The answer is surprisingly simple. It is about how things in the world come to be and cease to be, entstehen und vergehen. Whitehead uses several terms for this, 'becoming' and 'concrescence' being the most usual. I shall use both, but prefer the latter, as it connotes 'becoming concrete'. It is important to realise that for Whitehead coming to be and passing away are not separate, but two sides of the same coin. At literally the same time as it comes to be, an entity passes away. Becoming and perishing are inseparable. Why is this? In Aristotle, for example, things may come to exist, remain in existence for a period, often the while undergoing various changes, before ceasing to exist. Why are becoming and perishing,

1

I strongly prefer the usual spelling 'categorial' to Whitehead's idiosyncratic one, and so follow him only when forced by the rules of citation to do so. 
though not the same thing for Whitehead, simultaneous, and why is there no intervening persistence and change?

Part of the answer is that Whitehead's basic entities are not enduring substances but events. An enduring thing's changing, as we learn from Aristotle, consists in its having one property at one time and another property, incompatible with the first, at a later time, or being in one place at one time and in another place at another. But an event cannot change or move, since any incompatible properties exhibited at different times can safely be ascribed in the first instance to its then-current phases, as when a noise starts softly but increases in volume: the later phases are louder than the earlier. An enduring substance has no phases or temporal parts so only it can have the incompatible properties, and that constitutes change. As to why Whitehead prefers events to substances, that has to do partly with his critique of the theory of matter, but mainly to do with his espousal of the theory of relativity in physics, as analysed in full in his recent book The Principle of Relativity with Applications to Physical Science. Whitehead does not deny that there are enduring substances, notably ourselves, but he regards them as metaphysically posterior to events, and we shall consider his view later.

In his natural philosophy Whitehead espoused the view that all events have other events as proper parts. In other words, the mereology of events was atomless, or, we might say, gunky. But from Science and the Modern World onwards he has rejected this view and it is important to see why. The argument is given at 68-69 of $P R$. It is a modification of Zeno's arguments against motion, and has two premises: (1) In every becoming something becomes; (2) Every becoming is divisible into earlier and later phases which are themselves becomings. The argument is then that if, say, something takes a second to become, it presupposes what becomes in the first half-second. Iterating this argument by dichotomy and considering the beginning of the second, there is no answer to the question what becomes then, at the beginning of the second, because infinitely many things crowd towards the beginning, none of which is first. To say something becomes instantaneously (at the beginning of the second or at any other time) is no help because in continuous time there is no next instant at which something can become.

I have paraphrased this argument rather than quoted it, because I find Whitehead's own wording unclear. But to the extent that I understand his argument, I think it is simply unsound. The first premise is uncontroversial. The second premise is however not selfevident: why should not something come into being instantaneously, from nothing? And why is the fact that no instant has a next instant relevant? Suppose a temporally extended event lasts one second. Then its later phases indeed presuppose its earlier phases, but they are parts 
of it, and it is different from them because its later parts do not overlap with these earlier parts. If it has an instantaneous first part or temporal boundary, then such a first part came into existence from nothing, contrary to premise (2) but not contrary to reason. If it has no instantaneous first part then each of its later phases presupposes an infinite nest of earlier phases, all nicely fulfilling premise (2), but none the worse for that. Likewise if the event has an instantaneous last phase, it simply comes to an end at that instant and there is no subsequent becoming of it, contradicting premise (2). Or it has no last instant, and so no last phase, but is nevertheless over after a whole second. Similar arguments apply to instants intermediate between the beginning and the end of the event. We know from Whitehead's earlier natural philosophy that he did not believe in instants, and that was his reason then for not believing in instantaneous phases of events. But the Zenonian argument is supposed to be a priori and not dependent on debatable event mereology.

The upshot of Whitehead's argument is far-reaching. Firstly, it compels him to argue that the basic events have no proper parts: "Thus the ultimate metaphysical truth is atomism. The creatures are atomic" (35). But since the world is spatiotemporally continuous, "There is a becoming of continuity, but no continuity of becoming" (ibid.). This means that Whitehead is compelled to distinguish between the discontinuity of the events in spacetime and the continuity of the spacetime they occupy. This in turn forces him to adopt a metaphysical principle of which he had previously disapproved, the separation of space and time from their contents. Whereas in the natural philosophy spacetime was divided as events are divided, in the new atomistic theory of $P R$ the mereology of spacetime has to be treated differently from that of the occupying events. It is important to see that this conclusion is not forced on Whitehead. He could have maintained the mereological isomorphism of spacetime and events by claiming that spacetime too is atomic, but that its quanta are too small to be detected by us, at least with present means. That is indeed the view of many contemporary physicists. Nevertheless, by uncoupling the mereology of spacetime from that of its occupants, Whitehead intriguingly offers a rare and motivated instance of an ontology with what we might call extended simples. It also means that time comes not in a continuous flow as in Newton but in chunks, given with their parts but not serially. Whitehead calls this the epochal theory of time.

Presumably to distance his new view of events from the previous one, Whitehead invents a new term, 'actual occasions', for his atomic events. The adjective 'actual' stresses the ultimate reality of events: they are the building blocks of the universe, replacing Aristotelian substances and Newtonian matter in motion. In this review however I shall 
continue to use the word 'event' and understand it to mean Whitehead's atomic events. There is one other actual or ultimately real entity in Whitehead's metaphysics, which unlike the occasions is not in time and does not come to be or cease to be. This is God.

If events do not come about gradually and continuously, what is the word 'process' doing in Whitehead's title? Obviously it can mean the familiar kind of macroscopic going-on that gives the term its everyday use: the dissolving of salt in water, the rotation of the earth, the transport of oxygen from lungs to tissues, and the like. From his new atomistic standpoint Whitehead would take these to consist of large numbers of atomic events. But this everyday use is too uncontroversial and unspecific to warrant the first slot in the title. Rather, Whitehead uses the term to designate the very way in which events come to be. Since they do not come to be by temporal stages, 'process' must here have a new meaning. Whitehead describes process in this new sense in minute detail. "The actual entity is seen as a process: there is a growth from phase to phase; there are processes of integration and of reintegration" (283). Yet "This genetic passage from phase to phase is not in physical time" (ibid.). What can this mean? How is that Whitehead can calmly avail himself of the panoply of temporal terminology, phases, before and after, culmination and so on, and yet deny that the process is in time? The most benevolent interpretation must be that what he calls the phases of concrescence are to be understood as in some way ordered in a time-like manner, in which later phases somehow presuppose others. The actual succession of times, understood physically, is the succession of the temporal (and spatial) loci of concrescent events, and this is something else. While I am sceptical that Whitehead is entitled to simply help himself to the vocabulary of real processes in describing what is not a real process, let us afford him for now the benefit of the doubt and enquire further.

Each event comes about in virtue of this process, so what does it consist in? Whitehead's answer is that it consists in a complex (non-temporal) procedure of assimilating and integrating every object in an event's universe until it achieves a complete and consistent synthesis, the final phase of concrescence that Whitehead calls 'satisfaction', at which point the event perishes. This needs unpacking. Firstly, every event has a slightly different universe from every other. This is basically because of relativity. No event's universe contains any future event or any event in spacelike separation from it. In more prosaic terms, the events in a given event's universe are those in its backwards light-cone. Whitehead does not put it this way, but there is no other sensible interpretation. But alongside the events in an event's universe, there is a second array of objects, equally accessible to all events, that Whitehead calls eternal objects. With a caveat, these are Platonic ideas or forms. What make an event of 
the kind it is with the kind of characteristics it has are the eternal objects that it instantiates. Whitehead prefers to look at the instantiation relation from the other end and speaks instead of eternal objects' ingression into events. As their name implies, eternal objects are not in time, and so are as unlike events as can be. Among Whitehead's eight categories of existence, "actual entities and eternal objects stand out with a certain extreme finality" (22). The caveat about comparing eternal objects with Platonic forms concerns their modal status: Whitehead describes eternal objects not as actualities or res verae but as "Pure Potentials for the Specific Determination of Fact" (ibid.). Eternal objects are actualized by being instantiated, or ingressing into events. This raises the question as to what status an eternal object has that is not yet, maybe never, instantiated, since it is an unrealized potential, yet is not nothing, since the world may later progress to instantiate it. Whitehead's answer is that the eternal objects qua potentialities have a ground in actuality, namely in God. It is part of God's ontological job to be a repository or actual ground for eternal objects.

The events and eternal objects in an event's universe are accessible to it. Whitehead calls the relation of access prehension: the event prehends the objects in its universe, all of them. Prehension comes in two species and two logical flavours: prehensions of actual entities are physical prehensions, those of eternal objects are conceptual prehensions. A prehension may further be positive or negative. Whitehead also calls positive prehensions 'feelings'. Negative prehensions have no other name, but are said to "eliminate from feeling" (23). An event is distinguished from all others by the way in which it prehends the objects in its universe, and these prehensions determine its nature: the primary analysis or division of an event is into its prehensions, and the theory of prehensions forms the third part of the book's five parts.

The stages in the becoming of an event start with it prehending every object in its universe, eternal and temporal. Some of them it prehends positively, or feels. Where these are eternal objects, the event will tend to admit their ingression and eliminate the incompatible ones via negative prehensions. But the physical prehensions or feelings of earlier events determine an event's nature more directly, and it is a fair interpretation to say that physical feeling is interpretable as physical causation. There is then a cascading series of modifications in which an event's prehensions become more complex as it integrates the prehensions of those events it prehends and so on, until it attains a final stage at which all its prehensions, positive and negative, physical and conceptual, are integrated into a single coherent unity, the satisfaction, at which point it is finished, in both senses: it is completely itself, and it dies. Upon attaining this final state it becomes available or accessible for later 
events, as an object for them to prehend and take account of in their becoming. Each event comes to be in essentially the same kind of way: the differences are of material detail, not schematic form. The basic cell repeats itself formally over and again, and out of this repetition with endless variation the tissue of the world is woven. How the event "knows" when it is satisfied is discussed below.

It is worth comparing Whitehead's cosmology with that of Leibniz. Both are monadists: the basic realities are atomic. But Whitehead's are brief events, while Leibniz's are enduring substances. Leibniz's monads are windowless: they are as they are in virtue of their properties, and they stand in no causal or other external relation to anything, except for their dependence on God. Whitehead's events are all window: they are as they are by being a prehensive node in a network of relations to the eternal kinds and to their real antecedents. Their nature is to be related. It is through this emphasis on relatedness that Whitehead the metaphysician remains genetically linked to Whitehead the logician. There are other similarities, which will become plain.

\section{Panpsychism, Platonism, Teleology, Theism}

This is all very well, and Whitehead spares no rhetorical power in getting this picture across and comparing it favourably with antecedent accounts of becoming. But it raises a host of difficulties, and we need to mention some of the more pressing. The first is the use of psychological vocabulary. Though he does have neutral words like 'nexus' and 'contrast' in his vocabulary of categories, bloodless terms like 'relation' are put aside in favour of 'prehension', 'subjective form' (these both name categories), and 'feeling', 'emotion', 'value'. This is deliberate. Whitehead's events have, one and all, mental characteristics. Prehension is a species of intentionality, though Whitehead does not have that term in his vocabulary. Since roughly speaking you are your prehensions: there is nothing in time that is not through and through mental. Only the eternal objects are non-mental. Whitehead, like Leibniz, is a panpsychist. Nor is he abashed or embarrassed about it: on the contrary, he takes it as a positive feature of his account and proudly describes his view as a philosophy of organism.

Panpsychism never loses its power to shock. To suppose that there is something mental about fundamental particles like electrons or their constitutive events is to pass the straining point of common sense and espouse a seriously revisionary metaphysic. While there are worse positions for a metaphysician to espouse - idealism and dualism to name but two, 
and Whitehead thankfully skirts both - Whitehead's panpsychism does not, at least in $P R$, appear to derive from anxieties about accounting for the mind among matter, or dissatisfaction with emergentism, such as he will have encountered in Samuel Alexander's Space, Time and Deity. Rather he seems to have taken to it as a perfectly reasonable position. I confess to finding my disbelief in panpsychism so numbingly absolute that rational rebuttals come hard. Splutters and incredulous stares being no argument, I will simply register my dissent, appeal to common sense, and move on. I suspect that the panpsychist position, together with its attendant glutinous psychological vocabulary, may deter many of Whitehead's readers from going more deeply into his views, and I sympathize with their distaste, though it can and should be held in check while considering his merits.

The next point of demurral has to be Whitehead's Platonism. Platonism true or false is not a dispute that can be settled here: Platonists may skip a paragraph. But there are wellknown objections to Platonism, in particular the question of how we could come to have knowledge of eternal objects, that drive alternative theories of universals and philosophies of mathematics. That our access - indeed the access of all events - to eternal objects transpires by the mental relation of conceptual prehension simply adds to the mystery, though it does bring acquaintance and instantiation into the same boat, which I suppose counts as a theoretical simplification. However Whitehead then owes us an explanation of how I can think of the number two or the colour blue without myself becoming two or blue. Clearly some kind of cognitive detachment or indirection is involved. But we need a differentiating factor. This is what to expect when instantiation becomes a mental relation. If there are no eternal objects, then the qualitative character of events will need another explanation. It might be one involving relations almost as much as Whitehead's. But it will perforce be Aristotelian or Ockhamist. Personally I would opt for the latter, but these are anyway tried and tested metaphysical positions, and they dispense with conceptual prehension as a species, which cannot be bad.

There appears to be no systemic reason why every event should prehend every object in its universe. An event's prehensile environment is more plausibly limited by time, distance and type. Why should an event in the life of a proton prehend classical sonata form, that wellknown eternal object? It serves nothing. Nor are events deeply lost in its distant past and traceless in its recent past of any relevance to a new event. That would eliminate the need for negative prehensions, which seem to be there simply to make sure that events do not instantiate everything. If they do not start under that threat, "eliminating from feeling" is otiose. Of course having universal prehension renders it unnecessary to determine which 
objects are relevant and which are not. But the same kind of messiness by which real things come to pass must be mirrored in Whitehead's prehensive revisions and decisions in the genetic process of becoming, since the same phenomena have to be accounted for, only Whitehead adds in the unnecessary labour of also having to eliminate the fantastically irrelevant as well as the potentially but non-actually influential. This revision and that of the previous paragraph, if adopted, would mean that 'prehend' and 'feel' could be replaced by 'is causally influenced by'.

We mentioned earlier that how an event actually turns out may well not depend completely on its causal antecedents. Whitehead is not a causal determinist. Part of his motivation for this is the usual one of leaving room for freedom. He may also have been influenced by quantum theory. That theory's annus mirabilis of 1926 is perhaps too recent to have informed Whitehead's views in depth, but he clearly considers the quantist position affine with his event atomism. However, it turns out that according to Whitehead there is a reason why an event turns out just the way it does and not another way, even when not determined to be so by antecedent events. It is embodied in what he calls an event's 'subjective aim'. He could just as well have used the word 'telos': events are subject to final, as well as efficient causality. This comes out in the eighteenth category of explanation:

"That every condition to which the process of becoming conforms in any particular instance has its reason either in the character of some actual entity in the actual world of that concrescence, or in the character of the subject which is in process of concrescence. This category of explanation is termed the 'ontological principle.' It could also be termed the "principle of efficient, and final, causation"” (24).

What the past does not determine, the event's subjective aim or final cause does. Whitehead is a teleologist. Again, this is a debate too big to launch here, but I maintain that it is a retrograde step. The advance of science has seen the marginalisation and general rejection of teleology, and a fine-sounding name like 'the ontological principle' is not enough to rescue it. Whitehead appears unwilling to accept random, spontaneous or (wholly or partly) uncaused events, so he has to fish out teleology to cover the gap.

While in much of the work Whitehead retraces, from his new perspective, ground covered in the earlier philosophy of nature, the requirement of universality drives him in the apotheotic final part to move on to matters of values, ideals, and the divine. This part is unsatisfactorily terse, and we may hope that he expands on it in future writings. As many of his shorter essays attest, Whitehead can write clearly, attractively and sagely about history, art and culture. $P R$ is too grimly concerned with setting out the new cosmology to exhibit this 
kind of charm. The final chapter, 'God and the World', towards which the whole work has in a sense been moving, though it is only a few pages long, astonishingly is already inspiring a whole theological movement: process theology.

So, finally, there is God. Whitehead has no argument for the existence of a deity, even such an unconventional one as his. God is rendered plausible by His multiple metaphysical and valuative roles. For God is interestingly dual in Whitehead: He has a primordial nature, which is actual, eternal, and necessary, and a consequent nature, which is temporal, varying and contingent. The difference appears to be something like this. God is actual, and as such the ultimate ontological ground of all contingent actuality. He is also the ground of the laws of nature. So far, so scholastic. God is also the actual repository of the potentialities, some forever unactualized, which are the eternal objects. Leaving aside the somewhat demeaning janitorial nature of this role, let us turn to the more unconventional temporal side of God's nature. God changes as events occur and time goes by, and to the extent that what transpires is contingent, so is His consequent nature. Events perish as soon as they come to be. But they are in some way retained in God's consciousness, as a sort of indelible memory, and so attain a kind of immortality. This aspect of God's secondary role, that of a universal mnemonic repository, may perhaps hold consolatory significance for the bereaved, especially such as have lost loved ones in the Great War. Whether this is true or not, there appears to be no additional reason for this role in natural theology beyond God's usual omniscience. All told, the theistic component of Whitehead's metaphysics, much as it may excite theologians, will hold no appeal for those natural philosophers who abjure everything supernatural.

\section{Extension and Endurance}

To date we have dwelt on the more questionable aspects of Whitehead's metaphysics in $P R$, and they are neither few nor unimportant. But there are other aspects which are plausible, and yet others that are wholly admirable. To the plausible we may reckon the fourth part, 'The Theory of Extension'. This covers, from a modified perspective, similar ground to the physico-geometric studies in An Enquiry Concerning the Principles of Natural Knowledge, in which Whitehead deployed his novel method of extensive abstraction to define geometric concepts like those of point, line, straight line, and so on, on the basis of a mereology of extended events. Whitehead is indeed, along with his younger Polish contemporary Lesniewski, one of those developing mereology or formal part-whole theory, though his published exposition is en passant and leaves much to be desired in formal rigour. There may 
well be a formal mereology at the basis of Whitehead's long-anticipated fourth (geometrical) volume of Principia Mathematica, but this now alas seems unlikely to appear. Whitehead holds that geometrical abstractions are neither experienced nor unexperienced reals, but that a cunning logical construction based on extended events can recover all their logical and geometrical characteristics. In the Principles the objects over which he abstracted were concrete and extended events. After the Zenonian revision, the basis for extensive abstraction has been shifted from events to the spatiotemporal regions that they occupy, or as Whitehead likes saying, "enjoy". This is retrogressive from the earlier point of view: the spacetime in which events find themselves is now a presupposition of their actuality, not an abstraction from those events. What Whitehead does that is new is that, instead of dealing just with the mereology of regions, he expands the treatment to take in topological conceptions of connectedness and cognate concepts. In the Principles such topological concepts as were present were implicit, but now they are brought out explicitly. Whitehead is thus here offering valuable insights into a novel science that we might call mereotopology.

Another of the elements of Whitehead's metaphysics that rank as plausible concerns his account of how enduring objects like electrons, stars, trees and people arise from or are constituted by evanescent events. It comes to the fore in the third chapter of Part II, 'The Order of Nature'. This again continues a train of thought from the natural philosophy, where Whitehead described enduring objects as "the recognita amid events". ${ }^{2}$ Leaving the epistemological element of this aside, Whitehead ventures to explain objects in terms of what he calls societies of events. While it is not spelled out formally what it is to be a society, it seems to involve two aspects: one is a synchronic or near-synchronic one, whereby diverse events are bound communally together in what Whitehead calls a nexus. Where a collection of so connected events is complete, leaving out none in the nexus, that is the momentary basis of a society. Societies also have different kinds of tendency to engender their like, and as it were pass on their kind. Whitehead calls this genetic component serial order. In the simplest cases, events engender similar events in a chain, and we get the simplest substances: "each electron is a society of electronic occasions, and each proton is a society of protonic occasions" (91). Such a series may go on for a long time, yielding long-lived enduring objects. There are other forms of order, and they ramify in type and complexity. The sort which gives rise to ourselves is personal order. Aware of the complications and exceptions,

$$
\text { Principles, } 81 .
$$


Whitehead is fairly gentle and tentative in his assertions, but if one adopts an event metaphysics, an account broadly along these lines has to be right. Whitehead is also engagingly sensitive to issues of hierarchy, environment, supervenience and emergence, so while no precisely detailed theory is given, the discussion is full of suggestive ideas.

\section{Categorial Metaphysics}

Perhaps the most important and lasting legacy from Whitehead's metaphysics will be not its debatable content but the admirable way in which he goes about his task. To sustain his universalist ambitions, he reverts to methods of Aristotle, and sets out a conceptual framework consisting of a complex of categories. He stresses the importance of this approach:

"Philosophy will not regain its proper status until the gradual elaboration of categoreal schemes, definitely stated at each stage of progress, is recognized as its proper objective" (8).

Categories in the traditional sense, what Whitehead calls categories of existence, represent the most fundamental classes of entities. There are eight of these: actual entities, prehensions, nexūs, subjective forms, eternal objects, propositions, multiplicities, and contrasts (22). The last is in fact a ramified series of subcategories, representing contrasts of arbitrarily high rank. We have dealt with some of the eight and will not go into the rest. What Whitehead calls categories of explanation are not categories in this sense at all. Rather they appear to be axiomatic principles governing the interrelations of the instances of the categories of existence. We give the first two out of twenty-seven for illustrative flavour:

“(i) That the actual world is a process, and that the process is the becoming of actual entities. Thus actual entities are creatures; they are also termed 'actual occasions.'

“(ii) That in the becoming of an actual entity, the potential unity of many entities in disjunctive diversity - actual and non-actual-acquires the real unity of the one actual entity; so that the actual entity is the real concrescence of many potentials" (22).

Whitehead follows the categories of explanation by a further set of nine "Categoreal Obligations", which seem to have a sort of regulative character, although some of the obligations read like further explanations and others like definitions. I confess I have not been able to work out why Whitehead has this further group of "categories", and repeated reading has produced no enlightenment. 
The respective comparisons of categories of existence with primitive concepts and categories of explanation with axioms for the primitives indicates a greater affinity of $P R$ to the Whitehead of Principia and the Royal Society Memoir than the prose form would naturally lead one to expect. Whitehead's work, effusively prosy though it is, often reads as though he had a formal representation in mind. It is to be hoped that, despite his likely concern about getting his ideas out quickly in view of his advancing age, either he or one of his talented Harvard students will give us a proper formal-axiomatic treatment of the metaphysical ideas in this book.

Crowning Whitehead's categorial scheme is his grandly-named category of the ultimate. This is in truth not a category in any of the other senses, but a terse epitome of the scheme of becoming: an event comes to be by integrating the many objects of its universe into a wholly new entity, which is then available as an object for subsequent entities. Whitehead calls this 'creativity', and describes it thus:

"'Creativity' is the universal of universals characterizing ultimate matter of fact. It is that ultimate principle by which the many, which are the universe disjunctively, become the one actual occasion, which is the universe conjunctively." (21).

This ultimate metaphysical principle is the advance from a multiplicity, the objects prehended, to a new individual, integrating these objects by the texture of its prehensions and in the light of its subjective aim.

Calling a thumbnail of your metaphysical picture a 'category' is a misnomer. It is rather the schematic cell of all becoming, with the details left out. Whitehead's exalted denomination lends the thumbnail grandeur, but it remains just that, and does no useful work within the scheme. However its status as ultimate is highly interesting, even if Whitehead does not succeed in explaining clearly what it is to be ultimate. We learn something by contrast: Spinoza's God or Mr. Bradley's Absolute are also intended to be ultimates, though Whitehead rejects them as candidates because then "the ultimate is illegitimately allowed a final, 'eminent' reality, beyond that ascribed to any of its accidents" (7). He also says his category of the ultimate replaces Aristotle's primary substance (21), which may be why he elects to use 'category'. Creativity is, unlike God, the Absolute or an individual substance, not a thing: it is the process of becoming (in the non-temporal sense of course). Since there is no becoming without something that becomes, creativity is not self-sufficient like these other candidates. It is multiply instantiated, in every actual becoming, so it is a universal. In the abstract, it must be an eternal object, a potentiality. Like all universals, it becomes actual through instantiation, and how it in fact gets variously instantiated is the history of the world, 
the greatest of what Whitehead likes to call "adventures". Since how the world in fact turns out is highly contingent matter, the actuality of creativity is wholly accidental. The only possible exception to this would be God, but since God's consequent nature is determined by all the accidental happenings, even God is partly accidental in nature. God's primordial nature is non-temporal and so not subject to creativity, though since God is prehended by every event, if only through a glass darkly, and He is the source of laws and subjective aims, even He plays a role in creativity.

This peculiarly dependent nature of creativity inspires Whitehead to rhetorical heights:

"In all philosophic theory there is an ultimate which is actual in virtue of its accidents.

It is only then capable of characterization through its accidental embodiments, and apart from these accidents is devoid of actuality. In the philosophy of organism this ultimate is termed 'creativity'; and God is its primordial, non-temporal accident" (7).

This saying, dark though it is in some ways, is after all not so hard to understand. Creativity, being the form of every becoming, is actual through all becomings. It might have been otherwise instantiated, but is not.

Whitehead is here tapping a deep root of metaphysical insight which is rarely appreciated, let alone expressed with such relative clarity. It is that in addition to all the entities in the world, there are factors in virtue of which they are what and as they are, but these factors are not further entities to be set alongside the rest, on pain of regress. The fundamental constitutive role of these factors entitles us to call them 'ultimate', and their non-entity status means we should not give them "eminent reality". As to what or which they are, Whitehead misleads us by suggesting there is only one. His own category of the ultimate embodies more than one feature: it is articulated, and he admits as much by listing 'many' and 'one' alongside creativity. To do his idea justice, one would need to investigate the natures and interrelations of all of his categories of existence, which are after all there to put some flesh on the bare bones of the idea of creativity. There is further nothing creative about eternal objects, nor about God as primordial, so Whitehead should have embraced a pluralism of ultimates, marking the categorial differences and interactions. As to how the ultimate factors themselves are different, that can only be characterized in terms of logic and the very same factors. That such characterization is tightly impredicative is not a flaw but a sure sign that metaphysical bedrock has been reached. Whitehead's instinct is sound: as a true metaphysician, intent on a theory of everything, he wants his basic categories to leave nothing uncovered: "everything [...] shall have the character of a particular instance of the 
general scheme" (3). But this should cover the scheme and its components as well, and with creativity Whitehead gives us a gesture, not a theory. There is more work to be done, but Whitehead is man enough to recognise as much, and he stresses the halting nature of the advance towards metaphysical clarity:

"Metaphysical categories are not dogmatic statements of the obvious; they are tentative formulations of the ultimate generalities" (8).

\section{Post Scriptum}

There is much else in this extraordinarily rich book that bids fair to sustain scrutiny and commentary in years to come, and that this review has not touched. We have dwelt on some of its most distinctive elements, finding some unacceptable, others acceptable, and yet others inspirational. In the light of vigorous and increasingly influential anti-metaphysical movements now emerging in Vienna and Berlin, it is fair to say that metaphysics may well be set virtually to disappear for several decades: it is likely therefore that Whitehead's work will rapidly go out of fashion, and in his native land at least, already coming under the influence of the recently returned Viennese Wunderkind Wittgenstein, could be out of fashion for some time to come. Despite his cardinal contribution to the transparent idioms of modern symbolic logic, Whitehead has never been what one would call a linguistic philosopher, and in the Preface to $P R$ takes time to warn against "The trust in language as an adequate expression of propositions" (xiii). In this he is already parting company from his former collaborator $\mathrm{Mr}$. Russell, who appears to think the new logic gives us some kind of key to metaphysics. There is perhaps a chance that some young philosopher, such as Whitehead's talented recent Harvard supervisee Dr. Quine, will weather the European storm and emerge with a new and robust response to the Machian and neo-Humean metaphysical sceptics. But it is Whitehead who has in $P R$ demonstrated how to set about doing metaphysics in a properly systematic way, with due regard to both rigour and the probability of error. The content of Whitehead's metaphysic is disputable, and will be disputed by proponents and opponents of process metaphysics and other more specific positions within his work. It is the sagacity of his method and the interconnectedness of his themes that, I confidently predict, will ensure that Process and Reality comes to be reckoned as one of the high points of the Western philosophical tradition. 